\title{
Sex-Related Differences in COVID-19 Lethality
}

\author{
Claudia Penna ${ }^{1}$, Valentina Mercurio ${ }^{2}$, Carlo Tocchetti ${ }^{3}$, and Pasquale Pagliaro ${ }^{4}$ \\ ${ }^{1}$ University of Turin School of Medicine \\ ${ }^{2}$ Federico II University Hospital \\ ${ }^{3}$ University of Naples Federico II \\ ${ }^{4}$ University of Torino
}

May 26, 2020

\begin{abstract}
Many Western countries have been affected by the outbreak of COVID-19. Italy has been particularly hit at the beginning of the pandemic, immediately after China. In Italy and elsewhere women seem to be less affected then men by severe/fatal COVID-19 infection, regardless of their age. Despite the evidence that women and men are different fort this infection, very few studies consider different therapeutic approaches for the two sexes. Undoubtedly, understanding the mechanisms at the bases of these differences may help to find appropriate and sex specific therapies. Here we consider that other mechanisms but estrogen protection are involved. Several X-linked genes (such as ACE2) and Y-linked genes (SRY, SOX9) may explain sex differences. Cardiovascular comorbidities are among the major enhancers of virus lethality. In addition, the number of sex-independent non-genetic factors that can change susceptibility and mortality is enormous, and many other factors are likely to be considered, including gender and cultural habits in different countries.
\end{abstract}

\section{Sex-Related Differences in COVID-19 Lethality}

Claudia Penna ${ }^{1,2}$, Valentina Mercurio ${ }^{3}$, Carlo G. Tocchetti ${ }^{3,4}$ \& Pasquale Pagliaro $^{1,2}$

${ }^{1}$ Department of Clinical and Biological Sciences, University of Torino, Turin, Italy

${ }^{2}$ National Institute of Cardiovascular Researches, Bologna, Italy

${ }^{3}$ Department of Translational Medical Sciences, Federico II University, Naples, Italy

${ }^{4}$ Interdepartmental Center of Clinical and Translational Research, Federico II University, Naples, Italy

Address for correspondence:

Prof Pasquale Pagliaro, M.D., Ph.D.

Professor of Physiology

Coordinator of PhD Programme in Experimental Medicine and Therapy

Past-President of the Italian Society of Cardiovascular Researches

Dpt Clinical and Biological Sciences

University of Torino, Italy

https://dott-mts.campusnet.unito.it/do/home.plhttp://www.sirc-cardio.it

Tel. +390116705450

pasquale.pagliaro@unito.it 
OR

Carlo Gabriele Tocchetti, MD, PhD, FISC, FHFA

Vice Chair, ESC WG Myocardial Function

Ex Officio-Board Member of the ESC Council on Cardio-Oncology

Member of the HFA Study Group on Cardio-Oncology

2012-2016 Member of the HFA Translational Research Committee

Associate Professor of Medicine

Director, Cardio-Oncology Unit

Department of Translational Medical Sciences

Interdepartmental Center of Clinical and Translational Research (CIRCET)

Federico II University

Via Pansini 5

80131 Napoli, ITALY

Phone $+39-081-746-2242$

Fax $+39-081-746-2246$

carlogabriele.tocchetti@unina.it

\section{ABSTRACT}

Many Western countries have been affected by the outbreak of COVID-19. Italy has been particularly hit at the beginning of the pandemic, immediately after China. In Italy and elsewhere women seem to be less affected then men by severe/fatal COVID-19 infection, regardless of their age. Despite the evidence that women and men are different fort this infection, very few studies consider different therapeutic approaches for the two sexes. Undoubtedly, understanding the mechanisms at the bases of these differences may help to find appropriate and sex specific therapies. Here we consider that other mechanisms but estrogen protection are involved. Several X-linked genes (such as ACE2) and Y-linked genes (SRY, SOX9) may explain sex differences. Cardiovascular comorbidities are among the major enhancers of virus lethality. In addition, the number of sex-independent non-genetic factors that can change susceptibility and mortality is enormous, and many other factors are likely to be considered, including gender and cultural habits in different countries.

Key words: Cardiovascular comorbidities, ACE, ACE2, Androgens, Estrogens

\section{Introduction}

The outbreak of novel coronavirus disease 2019 (COVID-19) quickly turned into a pandemic, and Europe and U.S.A. have been particularly affected [Zhou et al. 2020b]. Sex differences are emerging in terms of case fatality (deaths/reported cases), and sex disaggregated data are now starting to be available for many countries. Looking at male/female ratio for death in confirmed cases it appears that the ratio is always above 1.1 in 34 out of the 35 countries that provide sex disaggregated data (only for Pakistan, the ratio is 0.9). Many European countries (Spain, Italy, England, Belgium, Greece, Denmark and The Netherlands) have a male/female ratio for death in confirmed cases equal or above 1.7 (https://globalhealth5050.org/covid19/, accessed on May $13^{\text {th }} 2020$ ). In particular, on May 11, 28.903 COVID-19 positive patients had died in Italy (Table 1). Their mean age was 80 years (median 81, range 0-100, IQR 74 -87) (https://www.iss.it/coronavirus, accessed on May $13^{\text {th }} 2020$ ). Deceased women were 10.934 (lethality $9.6 \%$ ), whereas men were 17.018 (lethality $17.1 \%$ ). For 951 Italian deaths, sex was not reported. The difference in lethality between sexes seems to suggest that women are less prone to develop severe complications that ultimately lead to death. The reasons for this 
sex-based tolerance are still unknown. Among Italian patients in the range 10-49 years, deceased women were about 84 over 32.345 ( $0.26 \%$ lethality), while in the range age of 50-90 years they were $7975 / 67.263$ (11.9\% lethality). Of note, men had a $0.89 \%$ lethality (225 deaths over 25276 cases) in the range $10-49$ years and $21.8 \%(15236 / 69844)$ in the range 50-90 years. Therefore, lethality seems to increase with age in both sexes, but it is 3.42 folds higher in young men than young women (10-49 years), and 1.84 folds in older men than in older women (50-90 years) (https://www.iss.it/coronavirus, accessed on May $13^{\text {th }} 2020$ ).

Although these are cumulative/raw data, they confirm that there is a reduced susceptibility of females to severe COVID-19 infection. Due to the differences between pre and post-menopausal phases [Horstman et al. 2012], it is reasonable to speculate that the potential role played by hormones may be present in protecting against severe outcome, but it is not the only factor. Therefore, we need to consider other possible reasons for this difference in sex-related lethality. First, is this difference confirmed also in populations from other countries? According to the latest publications, such differences in lethality between the 2 sexes have been shown elsewhere (see Table 1 andhttps://globalhealth5050.org/covid19/). For instance, in a number of different articles from China, similar data are reported [Chen et al. 2020a; Chen et al. 2020b; Guan et al. 2019; Huang et al. 2020; Wang et al. 2020; Zhou et al. 2020a]. In these studies, severe or deceased patients admitted to intensive care units (ICUs) were prevalently men, while women ranged between 30\% [Huang et al. 2020] and 42.2\% [Guan et al. 2019]. In the largest study available from China [Guan et al. 2019;], quite similar percentages to those reported for deceased women in Italy have been observed. Yet, in this latter study, the median age of patients was 47 years (IQR, 35-58), and the distribution between sexes according to age was not reported. For the US, sex disaggregated data on case fatality are not available, but deaths were $57 \%$ for males and $43 \%$ for women (https://globalhealth5050.org/covid19/, accessed on May 13 ${ }^{\text {th }} 2020$ ).

To sum up, currently available studies suggest that both young and older females are less susceptible to severe infection outcomes, regardless of their nationality. Both hospitalization in ICUs and death rates are different between sexes (https://globalhealth5050.org/covid19/ and Table 1). Similar observations were already reported for other coronavirus epidemics [Channappanavar et al. 2017].

Despite this striking evidences for this infection, very few studies consider different therapeutic approaches for the two sexes. As no specific therapeutics are yet proposed to treat Covid-19 and control disease evolution, a better understanding of the pathogenic mechanisms in the two sexes induced by SARS-CoV-2 is mandatory to characterize new targets.

\section{Why Are Less Women Than Men Dying of COVID-19?}

Both young and old women are dying less than matched age males. Beside hormone differences, which, however, do not appear to be the only factor, there are different potential mechanisms that may explain why women are less prone to severe COVID-19 infections.

The expression and activity of two factors may be considered, namely angiotensin-converting enzyme-2 (ACE2) and transmembrane protease, serine 2 (TMPRSS2) [Cheng et al. 2015; Kuba et al 2005]. While ACE2 is the receptor for the spike (S) protein of coronaviruses, TMPRSS2 splits the S-protein at sites $\mathrm{S} 1 / \mathrm{S} 2$ and S2, favoring the attachment and fusion of the virus to cell membranes, respectively. ACE2 is largely expressed in organs mainly targeted and damaged by SARS-CoV-2 [Pagliaro and Penna 2005]. Both ACE2 and TMPRSS2 have been proposed as modulators of the different susceptibility to SARS-CoV in both sexes [Hoffmann et al. 2020]. Indeed, the expression of ACE2 seems reduced in post-menopausal women. However, in some studies, no differences were detected for ACE and ACE2 between the 2 sexes, while a lower ACE2 serum activity was observed in younger compared to older women [Fernández-Atucha et al. 2017]. ACE2 is located on the $\mathrm{X}$ chromosome, and is one of the genes escaping $\mathrm{X}$ inactivation [Tukiainen et al. 2017]. Therefore, it can be hypothesized that the second $\mathrm{X}$ chromosome could protect women from fatal polymorphisms that make the infection more aggressive in males, e.g. by favoring viral binding. Indeed, in a recent study, worse outcome in older COVID-19 patients has been attributed to the presence of lower ACE-2 levels and the subsequent upregulation of Angiotensin II (Ang II) proinflammatory pathways throughout the body, which could make patients more prone to systemic "deleterious" effects of Ang II [AlGhatrif et al. 
2020]. ACE and ACE2 and their major products, Ang II and Ang-1-7, respectively, are linked in a sort of ying/yang process, when one decreases the other increases and viceversa [Pagliaro and Penna 2005; Koni and Miyamori 2007; Wakahara et al. 2016; Wang et al. 2015, 2016]. Whether ACE2 levels in the lung are related to the susceptibility and severity of COVID-19 infection is a matter of investigation [Gheblawi et al. 2020], and men may have higher expression of ACE2 in the lungs compared to women [Zhao et al. 2020], with potential important consequences on COVID-19 infections. Moreover, the different roles of membrane bound ACE2 and circulating ACE2 should be considered. Indeed, it has been proposed that soluble ACE2 could quench the coronavirus by limiting its attachment to cellular ACE2 [Monteil et al. 2020]. It is unknown whether circulating ACE2 levels in the two sexes are different. This would be an important piece of information as circulating ACE2 quenching the virus may limit the possibility for the virus to target other organs.

Although some animal and human studies suggest that TMPRSS2 is involved in determining severity of influenza [Cheng et al. 2015; Sakai et al. 2015], its role during coronavirus infections and in the modulation of COVID-19 severity is still unclear. Nevertheless, we must consider that TMPRSS2 is a testosterone regulated gene and may have a higher expression in men than in women [Tomlins et al. 2005].

Moreover, several other X-linked genes (such as ILs, FOXP3XIST, TLR7) and Y-linked genes (SRY, SOX9) may explain sex differences [Ghosh and Klein 2017]. These and other immune regulatory genes encoded by the $\mathrm{X}$ and $\mathrm{Y}$ chromosomes may explain lower viral loads and reduced inflammation in women compared to men [Conti and Younes 2020]. In particular, the two X chromosomes seem to regulate the immune system even if one of them is inactive. The $\mathrm{X}$ chromosome regulates the immune system also acting on other proteins, including CD40L, CXCR3 and TLR8. These can be up-regulated in women and can determine the response to viral infections as well as to vaccinations. A Differentially Expressed Genes (DEGs) network was constructed to identify a specific gene signature characterizing SARS-CoV-2 infection [Fagone et al. 2020]. Intriguingly, ten DEGs were modulated by sexual hormones, as Androgen Receptor regulated 6 DEGs (while CCL20 and CXCL1 genes were upregulated; THBD, HEY2, BBOX1 and MYLK were downregulated genes); whereas Estrogen Receptor 1 regulates 4 DEGs (while C3 and EDN1 genes were upregulated; PDK4 and VTCN1 were downregulated DEGs). Also, CD4 ${ }^{+} \mathrm{T}$ cells number differs between sexes being higher in women with a better immune response [Conti and Younes 2020]. Finally, the number of sex-independent non-genetic factors that can change susceptibility and mortality is enormous, and many other factors are likely to be considered, including gender and cultural habits in different countries. For example, an Outbreak in the Republic of Korea determined a high incidence of case in women due to social and religious events occurring in those days. [Report on the Epidemiological Features of Coronavirus Disease 2019 (COVID-19) Outbreak in the Republic of Korea from January 19 to March 2, 2020].

\section{Sex, Cardiovascular disease and Covid-19}

Cardiovascular disease is more prevalent in males, and subjects with cardiovascular dysfunction infected with SARS-CoV-2 have a worse prognosis. Among the deceased Covid-19 patients in Italy, less than $4 \%$ had no comorbidity, while more than $60 \%$ had three or more comorbidities. Among these, cardiovascular comorbidities were the most represented. These include arterial hypertension (about 70\% of deceased patients), followed by ischemic heart disease (about 30\%), atrial fibrillation (about 20\%), and heart failure (about 15\%) (https://www.iss.it/coronavirus, accessed on May 13 ${ }^{\text {th }} 2020$ ). Most of the deceased patients were elderly (over 65 years) and obese (in the Italian report, obesity is present in $12 \%$ of the deceased patients). All these conditions are characterized by a deranged ACE/ACE2 ratio [Koni and Miyamori 2007; Colucci et al 2011; Wang et al. 2015, 2016; Santos et al 2013, Wakahara et al. 2016;]. It appears that a deranged ACE/ACE2 ratio is responsible for a high incidence of dramatic ARDS and cardiovascular complications and the high lethality of Covid-19. Downregulation of ACE2 has been observed in pulmonary arterial hypertension and cigarette smoker patients [Yuan et al 2015; Horn et al 2020]. Therefore, we wonder if it is worth trying to reestablish an adequate ACE/ACE2 ratio to have better outcomes in Covid19. Indeed, Covid-19 depletes and downregulates ACE2 [Moccia et al 2020]. Therefore, a potential therapy could be the administration of drugs that activate ACE2, which has anti-inflammatory effects (Fig 1). Of note exercise is a natural way to increase the ACE2/ACE ratio [Crisafulli and Pagliaro 2020]. 


\section{Proposed drugs}

Drugs that can increase ACE2 activity include losartan (NCT04312009, NCT04311177, NCT04340557, NCT04343001; clinicaltrials.gov), diminazene diaceturate, resorcinolnaphthalein, and xantenone [Li et al. 2020]. Furthermore, recombinant ACE2 has been proposed in both pneumonia [Khan et al. 2017] and Covid19 [Monteil et al. 2020].

Currently, remdesevir, used against ebola, chloroquine/hydroxylchloroquine, used against malaria [Yazdany and Kim 2020; Luo et al. 2020], are being used for Covid-19 patients. A "cytokine storm" has been proposed several times as responsible of Covid- 19 lethality [Moccia et al. 2019]; therefore the anti-IL-6 receptor antibody, tocilizumab (used for the treatment of rheumatoid arthritis and CRS after CAR-T therapies), has been proposed in many clinical studies, and it is now in Phase II and Phase III studies in Covid-19 patients [Alvi et al. 2019; Lu et al. 2020; Luo et al. 2020]. Monoclonal antibodies, anti-IL-1 and anti-IL-6 and plasma derived from Covid-19 recovered patients have been proposed (https://www.sciencenews.org/article/coronaviruscovid-19-can-plasma-recovered-patients-treat-sick). Other anti-inflammatory drugs, comprising JAK inhibitors, and glucocorticoids may also be useful [Zhang et al. 2019]. Coagulopathies are also a prominent aspect of severe Covi-19 patients. Thus, anticoagulant treatment may decrease mortality [Tang et al. 2020]. While waiting for vaccines and new therapeutic strategies to fight this terrible pandemic different old antiviral options are under clinical trial as combination therapies. These include hydroxychloroquine given alone or with azithromycin, and remdesivir, as well as lopinavir/ritonavir alone or with interferon (ClinicalTrials.gov identifier: NCT04332094; NCT04332107; NCT04322123; NCT04335552; NCT04336332; NCT04339816). To the best of our knowledge none of these studies considered different therapeutic approaches for men and women. Moreover, for many of these drugs the effects on ACE/ACE2 ratio is unknown.

A recent study [Fagone et al. 2020] investigated the transcriptomic profile of primary human lung cells upon infection with SARS-CoV-2. In this study the transcriptomic profile of lung tissue from healthy women and men were compared with the transcriptomic induced by Covid-19. It emerged that at ages 40-60 years, the transcriptomic feature of female lung tissue was more similar to those induced by Covid-19 than in male tissue. The authors suggest that a lower threshold of acute response to SARS-CoV-2 infection in men may at least partly explain the lower lethality in women. Nevertheless, the potential factors that might induce this" COVID-19-resistant lung phenotype" in middle-aged women is not clear. In this study targeting the mammalian target of rapamycin (mTOR) pathway using sirolimus, appeared to be a promising therapeutic approach to fight Covid-19. Also mitogen-activated protein kinase kinase (MEK), I kappa B Kinase (IKK) and serine-threonine kinase (AKT) inhibitors have been proposed as candidate drugs [Fagone et al. 2020]. Of note some of these enzymese are linked to ACE2 anti-inflamamtory action [Dhawale et al. 2016]. Nevertheless, this study does not envisage different therapeutic approaches for men and women.

In conclusion, all the above mentioned drugs would warrant clinical studies. In particular, drugs that can affect ACE/ACE2 ratio may be considered (Fig 1). Besides a plethora of factors that may influence the outcome, sex must be one of the criteria to consider in order to select the appropriate therapy for the appropriate patients. Indeed, given the striking differences in lethality between the two sexes, we believe that studying the sex differences may help to find the appropriate therapies for all. Only large unbiased studies considering all the factors and hypotheses mentioned here concerning sex differences may explain why women are less at risk of dying from COVID-19 and might help to find the patient tailored therapy.

\section{Acknowledgment}

Drs Penna and Pagliaro report grants from the University of Torino, Ricerca Locale Ex-60\% (Grants: PAGP_RILO_16_01; PENC_RILO) and from MIUR (PAGP_FFABR_17_01 and by PENC_FFABR_17_01). Dr. Tocchetti reports personal fees from Alere, outside the submitted work. Dr. Mercurio reports a grant from SIC/MSD, ouside the submitted work.

Relationship: Dr. Tocchetti has a Canadian Patent No. 2,613,477, issued on Dec 3, 2013 Inventors: Nazareno Paolocci, David A Kass, Carlo G Tocchetti. Owner: Johns Hopkins University Entitled: THIOLSENSITIVE POSITIVE INOTROPES JHU Ref.: C04755-P04755-05 with royalties paid. No other relation- 
ships/conditions/circumstances that present a potential conflict of interest.

\section{Acronyms List}

ACE: angiotensin-converting enzyme

ACE2: angiotensin-converting enzyme-2

AKT: serine-threonine kinase

Ang II: angiotensin II

CAR-T: chimeric antigen receptor T-cells

Covid-19: coronavirus disease 2019

CRS: cytokine release syndrome

DEGs: differentially expressed genes

ICUs: intensive care units

IKK: I kappa B Kinase

MEK: mitogen-activated protein kinase kinase

mTOR: mammalian target of rapamycin

TMPRSS2: transmembrane protease, serine 2

\section{Legend}

Fig 1 Possible pivotal role of ACE2/ACE ratio in therapies against Covid-19 in the two sexes.

ReferencesAlGhatrif M, Cingolani O, Lakatta EG (2020). The Dilemma of Coronavirus Disease 2019, Aging, and Cardiovascular Disease: Insights From Cardiovascular Aging Science. JAMA Cardiol. doi: 10.1001/jamacardio.2020.1329. Alvi RM, Frigault MJ, Fradley MG, Jain MD, Mahmood SS, Awadalla M, Lee DH, Zlotoff DA, Zhang L, Drobni ZD, Hassan MZO, Bassily E, Rhea I, Ismail-Khan R, Mulligan CP, Banerji D, Lazaryan A, Shah BD, Rokicki A, Raje N, Chavez JC, Abramson J, Locke FL, Neilan TG (2019). Cardiovascular Events Among Adults Treated With Chimeric Antigen Receptor T-Cells (CAR-T). J Am Coll Cardiol 74(25):3099-3108. doi: 10.1016/j.jacc.2019.10.038. Channappanavar R, Fett C, Mack M, Ten Eyck PP, Meyerholz DK, Perlman S (2017). Sex-Based Differences in Susceptibility to Severe Acute Respiratory Syndrome Coronavirus Infection. J Immunol 198: 4046-53. Chen N, Zhou M, Dong X, Qu J, Gong F, Han Y, Qiu Y, Wang J, Liu Y, Wei Y, Xia J, Yu T, Zhang X, Zhang L (2020a). Epidemiological and clinical characteristics of 99 cases of 2019 novel coronavirus pneumonia in Wuhan, China: a descriptive study. Lancet 395(10223):507-513. doi: 10.1016/S0140-6736(20)30211-7. Chen T, Wu D, Chen H, Yan W, Yang D, Chen G, Ma K, Xu D, Yu H, Wang H, Wang T, Guo W, Chen J, Ding C, Zhang X, Huang J, Han M, Li S, Luo X, Zhao J, Ning Q (2020b). Clinical characteristics of 113 deceased patients with coronavirus disease 2019: retrospective study. BMJ. 368:m1091. doi: 10.1136/bmj.m1091. Cheng Z, Zhou J, To KK, Chu H, Li C, Wang D, Yang D, Zheng S, Hao K, Bosse Y, Obeidat M, Brandsma CA, Song YQ, Chen Y, Zheng BJ, Li L, Yuen KY (2015). Identification of TMPRSS2 as a susceptibility gene for severe 2009 pandemic A(H1N1) influenza and A(H7N9) influenza. J Infect Dis 212:1214-1221. doi:10.1093/infdis/jiv246. Colucci JA, Yuri Arita D, Sousa Cunha T, Seno Di Marco G, Vio CP, Pacheco-Silva A, Casarini DE (2011). Reninangiotensin system may trigger kidney damage in NOD mice. J Renin Angiotensin Aldosterone Syst 12:15-22. doi: 10.1177/1470320310375456. Epub 2010 Jul 13. PMID: 20627940. Conti P, Younes A (2020). Coronavirus COV-19/SARS-CoV-2 affects women less than men: clinical response to viral infection. $J$ Biol Regul Homeost Agents 34(2). doi: 10.23812/Editorial-Conti-3. Crisafulli A, Pagliaro P (2020). Physical activity/inactivity and COVID-19. Eur J Prev Cardiol 18:2047487320927597. doi: 10.1177/2047487320927597. Dhawale VS, Amara VR, Karpe PA, Malek V, Patel D, Tikoo K (2016). Activation of angiotensin-converting enzyme 2 (ACE2) attenuates allergic airway inflammation in rat asthma model. Toxicol Appl Pharmacol306:17-26. 
doi: 10.1016/j.taap.2016.06.026. Fagone P, Ciurleo R, Lombardo SD, Iacobello C, Palermo CI, Shoenfeld Y, Bendtzen K, Bramanti P, Nicoletti F (2020). Transcriptional landscape of SARS-CoV-2 infection dismantles pathogenic pathways activated by the virus, proposes unique sex-specific differences and predicts tailored therapeutic strategies. Autoimmun Rev 3:102571. doi: 10.1016/j.autrev.2020.102571. Fernández-Atucha A, Izagirre A, Fraile-Bermúdez AB, Kortajarena M, Larrinaga G, Martinez-Lage P, Echevarría E, Gil J (2017). Sex differences in the aging pattern of renin-angiotensin system serum peptidases. Biol Sex Differ 8:5. doi: 10.1186/s13293-017-0128-8. Gheblawi M, Wang K, Viveiros A, Nguyen Q, Zhong JC, Turner AJ, Raizada MK, Grant MB, Oudit GY (2020). Angiotensin Converting Enzyme 2: SARS-CoV-2 Receptor and Regulator of the Renin-Angiotensin System. Circ Res doi: 10.1161/CIRCRESAHA.120.317015. Ghosh S, Klein RS (2017). Sex Drives Dimorphic Immune Responses to Viral Infections. J Immunol 198:1782-1789. Guan WJ, Ni ZY, Hu Y, Liang WH, Ou CQ, He JX, Liu L, Shan H, Lei CL, Hui DSC, Du B, Li LJ, Zeng G, Yuen KY, Chen RC, Tang CL, Wang T, Chen PY, Xiang J, Li SY, Wang JL, Liang ZJ, Peng YX, Wei L, Liu Y, Hu YH, Peng P, Wang JM, Liu JY, Chen Z, Li G, Zheng ZJ, Qiu SQ, Luo J, Ye CJ, Zhu SY, Zhong NS; China Medical Treatment Expert Group for Covid-19 (2020). Clinical Characteristics of Coronavirus Disease 2019 in China. $N$ Engl J Med doi: 10.1056/NEJMoa2002032. Hilliard LM, Sampson AK, Brown RD, Denton KM. The "his and hers" of the renin-angiotensin system. Curr Hypertens Rep. 2013 Feb;15(1):71-9. doi: 10.1007/s11906012-0319-y. Hoffmann M, Kleine-Weber H, Schroeder S, et al. SARS-CoV2 cell entry depends on ACE2 and TMPRSS2 and is blocked by a clinically proven protease inhibitor. Cell 2020; 181(2) Horn EM, Chakinala M, Oudiz R, Joseloff E, Rosenzweig EB. Could pulmonary arterial hypertension patients be at a lower risk from severe COVID-19? (2020) Pulm Circ 10:2045894020922799. doi: 10.1177/2045894020922799. Horstman AM, Dillon EL, Urban RJ, Sheffield-Moore M (2012). The role of androgens and estrogens on healthy aging and longevity. J Gerontol A Biol Sci Med Sci 67: 1140-1152. Huang C, Wang Y, Li X, Ren L, Zhao J, Hu Y, Zhang L, Fan G, Xu J, Gu X, Cheng Z, Yu T, Xia J, Wei Y, Wu W, Xie X, Yin W, Li H, Liu M, Xiao Y, Gao H, Guo L, Xie J, Wang G, Jiang R, Gao Z, Jin Q, Wang J, Cao B (2020). Clinical features of patients infected with 2019 novel coronavirus in Wuhan, China. Lancet 395(10223):497-506. doi: 10.1016/S0140-6736(20)30183-5. Khan A, Benthin C, Zeno B, Albertson TE, Boyd J, Christie JD, Hall R, Poirier G, Ronco JJ, Tidswell M, Hardes K, Powley WM, Wright TJ, Siederer SK, Fairman DA, Lipson DA, Bayliffe AI, Lazaar AL (2017). A pilot clinical trial of recombinant human angiotensin-converting enzyme 2 in acute respiratory distress syndrome. Crit Care 21(1):234. doi: 10.1186/s13054-017-1823-x. Koni I, Miyamori I (2007). Synergistic expression of angiotensin-converting enzyme (ACE)and ACE2 in human renal tissue and confounding effects of hypertension on the ACE to ACE2 ratio.Endocrinology 148:2453-7. DOI: 10.1210/en.2006-1287. Kuba K, Imai Y, Rao S, Gao H, Guo F, Guan B, Huan Y, Yang P, Zhang Y, Deng W, Bao L, Zhang B, Liu G, Wang Z, Chappell M, Liu Y, Zheng D, Leibbrandt A, Wada T, Slutsky AS, Liu D, Qin C, Jiang C, Penninger JM (2005). A crucial role of angiotensin converting enzyme 2 (ACE2) in SARS coronavirus-induced lung injury. Nat Med 11(8):875-9. doi: 10.1038/nm1267. Li Y, Zhou W, Yang L, You R (2020). Physiological and pathological regulation of ACE2, the SARS-CoV-2 receptor. Pharmacol Resdoi.org/10.1016/j.phrs.2020.104833 Lu C.-C., Chen M.-Y., Chang Y.-L (2020). Potential therapeutic agents against COVID-19: what we know so far. J Chin Med Assoc10.1097/JCMA.0000000000000318 Luo P, Liu Y, Qiu L, Liu X, Liu D, Li J (2020). Tocilizumab treatment in COVID-19: A single center experience. J Med Virol doi: 10.1002/jmv.25801. Moccia F, Gerbino A, Lionetti V, Miragoli M, Munaron LM, Pagliaro P, Pasqua T, Penna C, Rocca C, Samaja M, Angelone T (2020). COVID-19-associated cardiovascular morbidity in older adults: a position paper from the Italian Society of Cardiovascular Researches.Geroscience doi: 10.1007/s11357-020-00198-w. Monteil V, Kwon H, Prado P, Hagelkrüys A, Wimmer RA, Stahl M, Leopoldi A, Garreta E, Hurtado Del Pozo C, Prosper F, Romero JP, Wirnsberger G, Zhang H, Slutsky AS, Conder R, Montserrat N, Mirazimi A, Penninger JM (2020). Inhibition of SARS-CoV-2 Infections in Engineered Human Tissues Using Clinical-Grade Soluble Human ACE2. CellS0092-8674(20)30399-8. doi: 10.1016/j.cell.2020.04.004. Pagliaro P, Penna C (2005). Rethinking the renin-angiotensin system and its role in cardiovascular regulation. Cardiovasc Drugs Ther. 2005 Jan;19(1):77-87. Report on the Epidemiological Features of Coronavirus Disease 2019 (COVID-19) Outbreak in the Republic of Korea from January 19 to March 2, 2020 (2020). Korean Society of Infectious Diseases; Korean Society of Pediatric Infectious Diseases; Korean Society of Epidemiology; Korean Society for Antimicrobial Therapy; Korean Society for Healthcare-associated Infection Control and Prevention; Korea 
Centers for Disease Control and Prevention. J Korean Med Sci.35(10):e112. doi: 10.3346/jkms.2020.35.e112. Sakai K, Sekizuka T, Ami Y, Nakajima N, Kitazawa M, Sato Y, Nakajima K, Anraku M, Kubota T, Komase K, Takehara K, Hasegawa H, Odagiri T, Tashiro M, Kuroda M, Takeda M. (2015). A mutant H3N2 influenza virus uses an alternative activation mechanism in TMPRSS2 knockout mice by loss of an oligosaccharide in the hemagglutinin stalk region. $J$ Virol89:5154-5158. doi:10.1128/JVI.00124-15. Santos SH, Andrade JM, Fernandes LR, Sinisterra RD, Sousa FB, Feltenberger JD, Alvarez-Leite JI, Santos RA (2013). Oral Angiotensin-(1-7) prevented obesity and hepatic inflammation by inhibition of resistin/TLR4/MAPK/NFxB in rats fed with high-fat diet.Peptides 46:47-52. doi: 10.1016/j.peptides.2013.05.010. Tang N., Bai H., Chen X., Gong J., Li D., Sun Z (2020). Anticoagulant treatment is associated with decreased mortality in severe coronavirus disease 2019 patients with coagulopathy $J$ Thromb Haemostdoi:10.1111/jth.14817. Tomlins SA, Rhodes DR, Perner S, Dhanasekaran SM, Mehra R, Sun XW, Varambally S, Cao X, Tchinda J, Kuefer R, Lee C, Montie JE, Shah RB, Pienta KJ, Rubin MA, Chinnaiyan AM (2005). Recurrent fusion of TMPRSS2 and ETS transcription factor genes in prostate cancer. Science310(5748):644-8. doi: 10.1126/science.1117679. Tukiainen T, Villani AC, Yen A, Rivas MA, Marshall JL, Satija R, Aguirre M, Gauthier L, Fleharty M, Kirby A, Cummings BB, Castel SE, Karczewski KJ, Aguet F, Byrnes A; GTEx Consortium; Laboratory, Data Analysis \&Coordinating Center (LDACC)-Analysis Working Group; Statistical Methods groups-Analysis Working Group; Enhancing GTEx (eGTEx) groups; NIH Common Fund; NIH/NCI; NIH/NHGRI; NIH/NIMH; NIH/NIDA; Biospecimen Collection Source Site-NDRI; Biospecimen Collection Source Site-RPCI; Biospecimen Core Resource - VARI; Brain Bank Repository-University of Miami Brain Endowment Bank; Leidos Biomedical — Project Management; ELSI Study; Genome Browser Data Integration \&Visualization-EBI; Genome Browser Data Integration \&Visualization-UCSC Genomics Institute, University of California Santa Cruz, Lappalainen T, Regev A, Ardlie KG, Hacohen N, MacArthur DG (2017) Landscape of X chromosome inactivation across human tissues. Nature 550(7675):244-248. doi: 10.1038/nature24265. Erratum in:Nature. 2018 Mar 7;555(7695):274. Wang G, Zhang Q, Yuan W, Wu J, Li C (2016). Enalapril protects against myocardial ischemia/reperfusion injury in a swine model of cardiac arrest and resuscitation. Int J Mol Med. 38(5):1463-1473. doi: 10.3892/ijmm.2016.2737. Wang D, Hu B, Hu C, Zhu F, Liu X, Zhang J, Wang B, Xiang H, Cheng Z, Xiong Y, Zhao Y, Li Y, Wang X, Peng Z (2020). Clinical Characteristics of 138 Hospitalized Patients With 2019 Novel Coronavirus-Infected Pneumonia in Wuhan, China. JAMA. doi: 10.1001/jama.2020.1585. Wang J, Li N, Gao F, Song R, Zhu S, Geng Z (2015). Balance between angiotensin converting enzyme and angiotensin converting enzyme 2 in patients with chronic heart failure. J Renin Angiotensin Aldosterone Syst 16:553-8. doi:10.1177/1470320315576257. Yazdany J, Kim AHJ (2020). Use of Hydroxychloroquine and Chloroquine During the COVID-19 Pandemic: What Every Clinician Should Know.Ann Intern Med. 2020 Mar 31. doi: 10.7326/M20-1334. [Epub ahead of print] Yuan YM, Luo L, Guo Z, Yang M, Ye RS, Luo C (2015). Activation of renin-angiotensin-aldosterone system (RAAS) in the lung of smoking-induced pulmonary arterial hypertension (PAH) rats. J Renin Angiotensin Aldosterone Syst 16:249-53. doi: 10.1177/1470320315576256. Zhang W, Zhao Y, Zhang F, Wang Q, Li T, Liu Z, Wang J, Qin Y, Zhang X, Yan X, Zeng X, Zhang S (2020). The use of anti-inflammatory drugs in the treatment of people with severe coronavirus disease 2019 (COVID-19): The Perspectives of clinical immunologists from China. Clin Immunol214:108393. doi: 10.1016/j.clim.2020.108393. Zhao Y, Zhao Z, Wang Y, Zhou Y, Ma Y, Zuo W (2020). Single-cell RNA expression profiling of ACE2, the putative receptor of Wuhan 2019-nCov,bioRxiv; 10.1101/2020.01.26.919985 Zhou F, Yu T, Du R, Fan G, Liu Y, Liu Z, Xiang J, Wang Y, Song B, Gu X, Guan L, Wei Y, Li H, Wu X, Xu J, Tu S, Zhang Y, Chen H, Cao B (2020). Clinical course and risk factors for mortality of adult inpatients with COVID-19 in Wuhan, China: a retrospective cohort study. Lancet395(10229):1054-1062. doi: 10.1016/S0140-6736(20)30566-3. Zhou P, Yang XL, Wang XG, Hu B, Zhang L, Zhang W, Si HR, Zhu Y, Li B, Huang CL, Chen HD, Chen J, Luo Y, Guo H, Jiang RD, Liu MQ, Chen Y, Shen XR, Wang X, Zheng XS, Zhao K, Chen QJ, Deng F, Liu LL, Yan B, Zhan FX, Wang YY, Xiao GF, Shi ZL (2020). A pneumonia outbreak associated with a new coronavirus of probable bat origin. Nature 579(7798):270-273. doi: 10.1038/s41586-020-2012-7. Epub 2020 Feb 3. PMID: 32015507; PMCID: PMC7095418. 
Same or different therapy against Covid-19 in the two sexes?

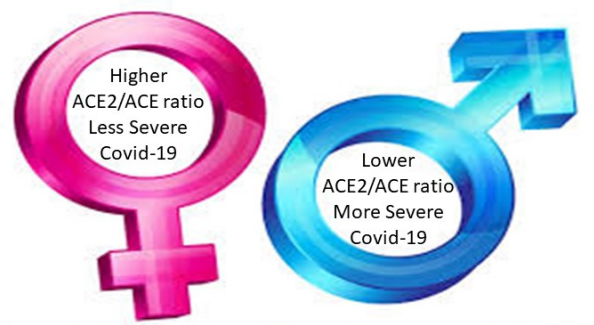

Can administration of drugs that upregulate ACE2 have anti-inflammatory effects?

\section{Hosted file}

table covid.docx available at https://authorea.com/users/326577/articles/454391-sex-relateddifferences-in-covid-19-lethality 